\title{
Antimycin A as a mitochondrial electron transport inhibitor prevents the growth of human lung cancer A549 cells
}

\author{
YONG HWAN HAN, SUHN HEE KIM, SUNG ZOO KIM and WOO HYUN PARK
}

\author{
Department of Physiology, Medical School, Institute for Medical Sciences, Centers for Healthcare \\ Technology Development, Chonbuk National University, JeonJu 561-180, Republic of Korea
}

Received April 7, 2008; Accepted June 2, 2008

DOI: 10.3892/or_00000061

\begin{abstract}
Antimycin A (AMA) inhibits mitochondrial electron transport between cytochromes $b$ and $c$. We evaluated the effects of AMA on the growth of human pulmonary adenocarcinoma A549 cells in relation to cell cycle and apoptosis. Treatment with 2-100 $\mu \mathrm{M}$ AMA significantly inhibited the cell growth of A549 for $72 \mathrm{~h}$. DNA flow cytometry indicated that AMA slightly induced a G1 phase arrest of the cell cycle for $72 \mathrm{~h}$. Treatment with $50 \mu \mathrm{M}$ AMA induced apoptosis of $\sim 17 \%$ in view of annexin V-staining cells. The dose of $50 \mu \mathrm{M}$ AMA also induced loss of the mitochondrial membrane potential $\left(\Delta \Psi_{\mathrm{m}}\right)$ of $\sim 38 \%$. The intracellular reactive oxygen species (ROS) levels including $\mathrm{O}_{2}{ }^{*-}$ were significantly increased in AMA-treated A549 cells. In conclusion, AMA inhibited the growth of A549 cells via inducing cell cycle arrest as well as triggering apoptosis. Growth inhibition in AMAtreated A549 cells was accompanied by an increase in ROS levels.
\end{abstract}

\section{Introduction}

Antimycin A (AMA) is a product predominantly composed of antimycin A1 and A3, which are derived from Streptomyces kitazawensis (1). AMA inhibits succinate and NADH oxidase, and mitochondrial electron transport between cytochromes b and c (2-4). The inhibition of electron transport causes a collapse of the proton gradient across the mitochondrial inner membrane, thereby breaking down the mitochondrial

Correspondence to: Dr Woo Hyun Park, Department of Physiology, Medical School, Chonbuk National University, JeonJu 561-180, Republic of Korea

E-mail: parkwh71@chonbuk.ac.kr

Abbreviations: AMA, antimycin A; ROS, reactive oxygen species; FBS, fetal bovine serum; MTT, 3-(4,5-dimethylthiazol-2yl)-2,5-diphenyltetrazolium bromide; PI, propidium iodide; FITC, fluorescein isothiocyanate; $\mathrm{H}_{2}$ DCFDA, 2',7'-dichlorodihydrofluorescein diacetate; DHE, dihydroethidium

Key words: antimycin A, cell cycle, apoptosis, A549, reactive oxygen species membrane potential $\left(\Delta \Psi_{\mathrm{m}}\right)(2,3,5)$. This inhibition also results in the production of reactive oxygen species (ROS) $(5,6)$. ROS such as hydrogen peroxide $\left(\mathrm{H}_{2} \mathrm{O}_{2}\right)$, superoxide anion $\left(\mathrm{O}_{2}{ }^{-}\right)$ and the hydroxyl radical $\left({ }^{\circ} \mathrm{OH}\right)$ are formed as by-products of mitochondrial respiration or oxidases such as nicotine adenine diphosphate (NADPH) oxidase, xanthine oxidase (XO) and arachidonic acid oxygenases (7). A change in the redox state of the tissue implies a change in ROS generation or metabolism. Principal metabolic pathways include superoxide dismutase (SOD), which is expressed as extracellular, intracellular and mitochondrial isoforms. These isoforms metabolize $\mathrm{O}_{2}{ }^{--}$to $\mathrm{H}_{2} \mathrm{O}_{2}$. Further metabolism by peroxidases that include catalase and glutathione (GSH) peroxidase yields $\mathrm{O}_{2}$ and $\mathrm{H}_{2} \mathrm{O}(8)$. Cells possess antioxidant systems to control the redox state, which is important for their survival. Evidence indicate that either the presence of excessive ROS or the collapse of mitochondrial membrane potential $\left(\Delta \Psi_{\mathrm{m}}\right)$ opens the mitochondrial permeability transition pore, which is accompanied by the release of proapoptotic molecules such as cytochrome $\mathrm{c}$ into the cytoplasm $(9,10)$. Since AMA acts directly on the mitochondria, AMA-induced apoptosis has been reported in many experiments, including our report on As4.1 juxtaglomerular cells (11-16).

The cell cycle in eukaryotes is regulated by cyclindependent kinases (CDKs). The cyclins, members of the cell cycle regulators, bind to and activate CDKs. Sequential formation, activation and subsequent inactivation of CDKs and cyclins are critical for control of the cell cycle (17). Cyclindependent kinase inhibitors (CDKI), p21 and p27, can also play a key role in controlling cell cycle progression by negatively regulating cyclin-dependent kinase (CDK) activities $(18,19)$. Evidence are now accumulating that ROS may also play a role as cell signaling molecules $(20,21)$ and as such they may have a role in cell cycle progression.

Lung cancer is the major cause of cancer death in developed countries. There are various novel therapeutic strategies currently under consideration, as the clinical use of cytotoxic drugs is limited due to intrinsic or acquired resistance and toxicity (22). A better understanding of the molecular mechanisms of cytotoxic drug action has shed light on treatments of lung cancer, and novel agents that target specific intracellular pathways related to the distinctive properties of cancer cells continue to be developed. In addition, the study on the molecular mechanisms of mitochondrial damage agents in lung cancer cells will shed light on the development of drugs 
related to mitochondrial damage for the treatment of lung cancer patients.

In the present study, we evaluated the effects of AMA as an inhibitor of mitochondrial electron transport on the growth of human lung cancer A549 cells and investigated its antigrowth mechanism in relation to cell cycle and apoptosis.

\section{Materials and methods}

Cell culture. The human pulmonary adenocarcinoma A549 cell line was obtained from the ATCC (HTB56) and was maintained in a humidified incubator containing $5 \% \mathrm{CO}_{2}$ at $37^{\circ} \mathrm{C}$. A549 cells were cultured in RPMI-1640 supplemented with $10 \%$ fetal bovine serum (FBS) and $1 \%$ penicillinstreptomycin (Gibco BRL, Grand Island, NY). Cells were routinely grown in 100-mm plastic tissue culture dishes (Nunc, Roskilde, Denmark) and harvested with a solution of trypsinEDTA while in a logarithmic phase of growth. Cells were maintained in these culture conditions for all experiments.

Reagents. AMA was purchased from Sigma-Aldrich Chemical Company (St. Louis, MO). AMA was dissolved in ethanol at $2 \times 10^{-2} \mathrm{M}$ as a stock solution. The stock solution was wrapped in foil and kept at $4^{\circ} \mathrm{C}$ or $-20^{\circ} \mathrm{C}$.

Cell growth and viability assay. The effect of AMA on the growth and viability of A549 cells was determined by trypan blue exclusion cell counting and by measuring 3-(4,5dimethylthiazol-2-yl)-2,5-diphenyltetrazolium bromide (MTT) dye absorbance of living cells as previously described (23), respectively. In brief, cells were seeded in a 24-well plate (Nunc) for cell counting or in a 96-well microtiter plate for MTT assay. After exposure to the doses of AMA (0-100 $\mu \mathrm{M})$ for 24-72 h, cells in the 24- or 96-well plates were collected with trypsin digestion for trypan blue exclusion cell counting or for MTT assay. MTT (20 $\mu \mathrm{l})$ (Sigma) solution $(2 \mathrm{mg} / \mathrm{ml}$ in PBS) was added to each well of the 96-well plate. The plate was incubated for 3 or 4 additional hours at $37^{\circ} \mathrm{C}$. The MTT solution in the medium was withdrawn by pipetting. To achieve solubilization of the formazan crystals that formed in viable cells, 100 or $200 \mu 1$ of DMSO were added to each well. The optical density of each well was measured at $570 \mathrm{~nm}$ using a microplate reader (Spectra MAX 340, Molecular Devices Co., Sunnyvale, CA).

Cell cycle distribution analysis. Cell cycle distribution was determined by DNA staining with propidium iodide (PI, Sigma-Aldrich) $(\mathrm{Ex} / \mathrm{Em}=488 \mathrm{~nm} / 617 \mathrm{~nm})$ as previously described (24). PI is a fluorescent biomolecule that can be used to stain DNA. In brief, $1 \times 10^{6}$ cells were incubated with the designated doses of AMA for 24-72 h. The cells were washed with phosphate-buffered saline (PBS) and fixed in $70 \%$ ethanol. Cells were washed again with PBS and then incubated with PI $(10 \mu \mathrm{g} / \mathrm{ml})$ with the simultaneous treatment of RNase at $37^{\circ} \mathrm{C}$ for $30 \mathrm{~min}$. The percentages of cells in different phases of the cell cycle were measured with a FACStar flow cytometer (Becton-Dickinson, San Jose, CA) and analyzed using lysis II and CellFIT software (BectonDickinson) or ModFit software (Verity Software House, Inc., $\mathrm{ME})$.
Annexin $V$ staining. Apoptosis was determined by staining cells with annexin V-fluorescein isothiocyanate (FITC) $(\mathrm{Ex} / \mathrm{Em}=488 \mathrm{~nm} / 519 \mathrm{~nm})$, because annexin $\mathrm{V}$ can be used to identify the externalization of phosphatidylserine during the progression of apoptosis and, therefore, can detect cells during the early phases of apoptosis. In brief, cells were incubated with the designated doses of AMA for $72 \mathrm{~h}$. Cells were washed twice with cold PBS and then resuspended in $500 \mathrm{ml}$ of binding buffer (10 mM HEPES/NaOH $\mathrm{pH} 7.4$, $\left.140 \mathrm{mM} \mathrm{NaCl}, 2.5 \mathrm{mM} \mathrm{CaCl}_{2}\right)$ at a concentration of $1 \times 10^{6}$ cells/ml. Annexin V-FITC (5 $\mu$ l) (PharMingen, San Diego, CA) was then added to these cells, which were analyzed with a FACStar flow cytometer (Becton-Dickinson).

Measurement of the mitochondrial membrane potential $\left(\Delta \Psi_{m}\right)$. The mitochondrial membrane was monitored using the Rhodamine 123 fluorescent dye $(\mathrm{Ex} / \mathrm{Em}=485 \mathrm{~nm} / 535 \mathrm{~nm})$, a cell-permeable cationic dye, which preferentially enters mitochondria based on the highly negative mitochondrial membrane potential $\left(\Delta \Psi_{\mathrm{m}}\right)$. Depolarization of the mitochondrial membrane potential $\left(\Delta \Psi_{\mathrm{m}}\right)$ results in loss of Rhodamine 123 from the mitochondria and a decrease in intracellular fluorescence. In brief, cells were incubated with the designated doses of AMA for $72 \mathrm{~h}$. Cells were washed twice with PBS and incubated with Rhodamine $123(0.1 \mu \mathrm{g} / \mathrm{ml}$, Sigma $)$ at $37^{\circ} \mathrm{C}$ for $30 \mathrm{~min}$. Rhodamine 123 staining intensity was determined by a FACStar flow cytometer (Becton-Dickinson).

Detection of intracellular general ROS and $\mathrm{O}_{2}{ }^{\circ}$ concentration. Intracellular general ROS such as $\mathrm{H}_{2} \mathrm{O}_{2},{ }^{\circ} \mathrm{OH}$ and $\mathrm{ONOO}^{*}$ were detected by means of an oxidation-sensitive fluorescent probe dye, 2',7'-dichlorodihydrofluorescein diacetate $\left(\mathrm{H}_{2} \mathrm{DCFDA}\right)$ (Invitrogen Molecular Probes, Eugene, OR). $\mathrm{H}_{2}$ DCFDA was deacetylated intracellularly by nonspecific esterase, which was further oxidized by cellular peroxides, yielding 2,7-dichlorofluorescein (DCF), a fluorescent compound $(\mathrm{Ex} / \mathrm{Em}=495 \mathrm{~nm} / 529 \mathrm{~nm})$. DCF is poorly selective for superoxide anion radical $\left(\mathrm{O}_{2}{ }^{-}\right)$. In contrast, dihydroethidium $(\mathrm{DHE})(\mathrm{Ex} / \mathrm{Em}=518 \mathrm{~nm} / 605 \mathrm{~nm})($ Invitrogen Molecular Probes) is a fluorogenic probe that is highly selective for $\mathrm{O}_{2}{ }^{-}$among ROS. DHE is cell-permeable and reacts with superoxide anion to form ethidium, which in turn intercalates in deoxyribonucleic acid, thereby exhibiting a red fluorescence. In brief, cells were incubated with the designated doses of AMA for $72 \mathrm{~h}$. Cells were then washed in PBS and incubated with $20 \mu \mathrm{M} \mathrm{H}_{2} \mathrm{DCFDA}$ or $5 \mu \mathrm{M}$ DHE at $37^{\circ} \mathrm{C}$ for $30 \mathrm{~min}$ according to the manufacturer's instructions. DCF and red fluorescence were detected using a FACStar flow cytometer (Becton-Dickinson). For each sample, 5,000 or 10,000 events were collected. ROS and $\mathrm{O}_{2}{ }^{-}$levels were expressed as mean fluorescence intensity (MFI), which was calculated by CellQuest software.

Statistical analysis. Results shown in the figures represent the mean of at least two independent experiments; bar, \pm SD. Microsoft Excel or Instat software (GraphPad Prism4, San Diego, CA) was used to analyze the data. Student's t-test or one-way analysis of variance (ANOVA) was used for parametric data. Statistical significance was defined as $\mathrm{p}<0.05$. 
A

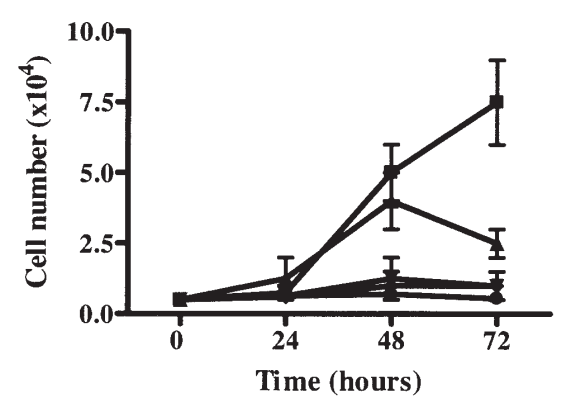

B

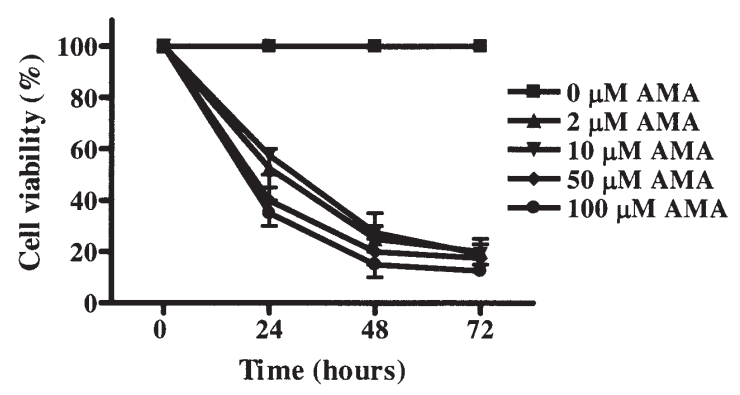

Figure 1. Effects of AMA on the growth and viability of A549 cells in vitro. Exponentially-growing cells were treated with the indicated concentrations of AMA for the indicated times. Cell number (A) and viability (B) were determined as described in Materials and methods.

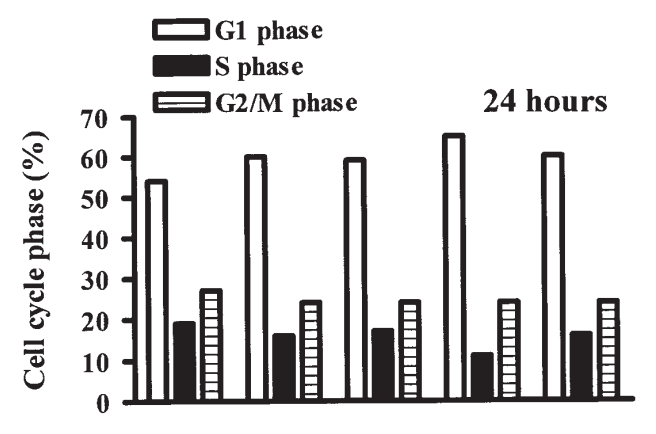

48 hours

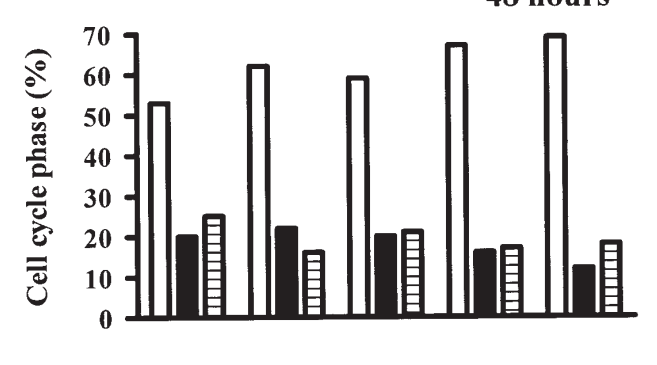

72 hours

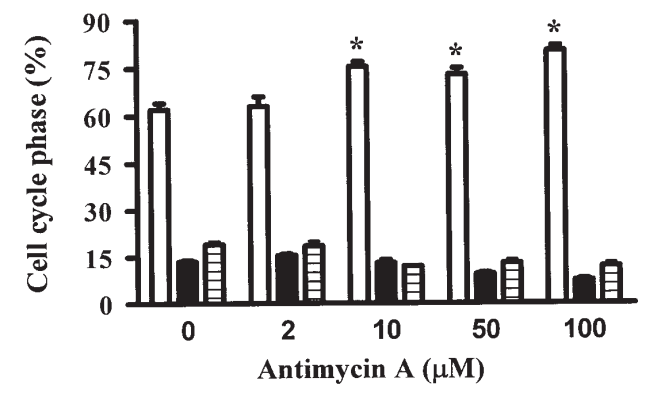

Figure 2. Effects of AMA on the cell cycle distribution in A549 cells. Exponentially-growing cells were treated with the indicated concentrations of AMA for 24-72 h. Changes in cell cycle phase distribution were assessed by DNA flow cytometry. "P $<0.05$ compared with the AMA-untreated control cell group.

\section{Results}

Effects of AMA on the growth and viability of A549 cells. We examined the effect of AMA on the growth of A549 cells by trypan blue cell counting. Treatment with $2 \mu \mathrm{M}$ AMA significantly inhibited the cell growth of A549 after $48 \mathrm{~h}$ in culture (Fig. 1A). The cell growth was completely inhibited at $10 \mu \mathrm{M}$ (Fig. 1A). When the viability of A549 cells after treatment with AMA was investigated by MTT assay, the viability was reduced following treatment with $2 \mu \mathrm{M}$ AMA from the beginning time of incubation (Fig. 1B).

Effects of AMA on cell cycle distribution in A549 cells. We examined the in vitro effect of AMA on the cell cycle distribution in A549 cells. As shown in Fig. 2, DNA flow cytometry indicated that treatment with AMA slightly induced a G1 phase arrest of the cell cycle for the incubation time of $72 \mathrm{~h}$, but $2 \mu \mathrm{M}$ AMA did not induce the specific cell cycle arrest at $72 \mathrm{~h}$.

Effects of AMA on apoptosis and the mitochondrial membrane potential $\left(\Delta \Psi_{m}\right)$ in A549 cells. We determined whether AMA induces apoptosis in A549 cells. When A549 cells were stained with annexin V-FITC, the proportion of annexin V-staining cells in AMA-treated cells was increased in a dose-dependent manner (Fig. 3A), which indicates that AMA-induced A549 cell death occurred via apoptosis. In addition, treatment with 10-100 $\mu$ M AMA significantly induced loss of the mitochondrial membrane potential $\left(\Delta \Psi_{\mathrm{m}}\right)$ in A549 cells (Fig. 3B). Following exposure to $50 \mu \mathrm{M}$ AMA for $72 \mathrm{~h}$, the percentage of cells staining negative for Rhodamine 123 was $\sim 38 \%$.

Effects of AMA on intracellular ROS levels in A549 cells. To assess the production of intracellular general ROS in AMAtreated A549 cells, we used $\mathrm{H}_{2}$ DCFDA fluorescence dye. As shown in Fig. 4A, the intracellular ROS levels were significantly increased in A549 cells treated with AMA for $72 \mathrm{~h}$. In addition, red fluorescence derived from DHE, which reflected $\mathrm{O}_{2}{ }^{-}$accumulation, was significantly increased in A549 cells treated with $50 \mu \mathrm{M}$ AMA for $72 \mathrm{~h}$ (Fig. 4B).

\section{Discussion}

In the present study, we focused on the effects of AMA on the growth of human pulmonary adenocarcinoma A549 cells in view of cell cycle arrest and apoptosis. We have demonstrated that AMA decreased the growth of lung cancer cells by inducing a G1 arrest of the cell cycle and by 
A

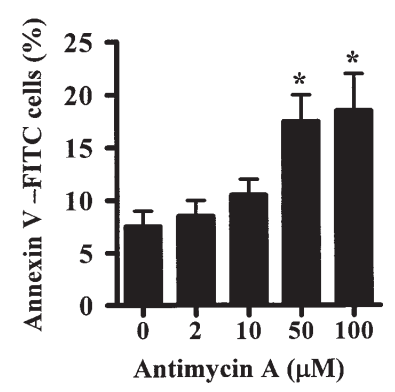

B

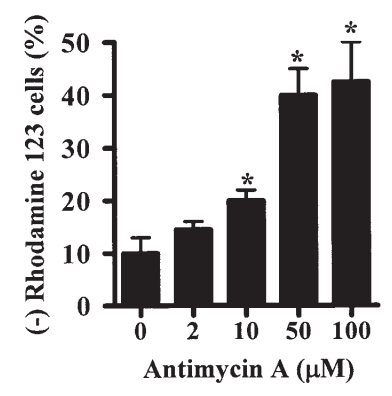

$\mathbf{A}$

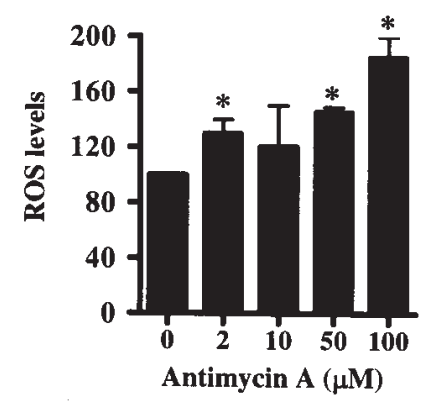

B

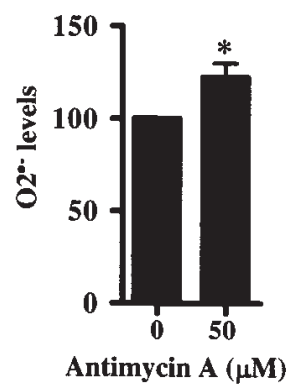

Figure 3. Effects of AMA on apoptosis and the mitochondrial membrane potential $\left(\Delta \Psi_{\mathrm{m}}\right)$ in A549 cells. Exponentially-growing cells were treated with the indicated concentrations of AMA for $72 \mathrm{~h}$. (A) The graph shows the percentages of annexin V-positive cells in AMA-treated cells. (B) The graph shows the percentages of Rhodamine 123-negative [mitochondrial membrane potential $\left(\Delta \Psi_{\mathrm{m}}\right)$ loss] cells in AMA-treated cells. ${ }^{*} \mathrm{P}<0.05$ compared with the AMA-untreated control cell group.

triggering apoptosis. Treatment with 2-100 $\mu \mathrm{M}$ AMA significantly inhibited the cell growth of A549. Suppression of cell growth by AMA can be explained in part by arrest during the cell cycle. Our cell cycle analysis has revealed that AMA was able to induce a G1 phase arrest of the cell cycle for $72 \mathrm{~h}$. Treatment with $50 \mu \mathrm{M}$ AMA resulted in the inhibition of A549 cell growth by $>70 \%$ compared with the control cells, but this concentration of AMA induced apoptosis of $\sim 17 \%$ in view of annexin $\mathrm{V}$ staining. Therefore, to explain the mechanism of the inhibition of cell growth by AMA, the G1 phase arrest of the cell cycle can be considered as a pathway to suppressing the growth of lung cancer A549 cells. However, although treatment with $2 \mu \mathrm{M}$ AMA had a strong effect on the inhibition of A549 cell growth, it did not significantly induce any specific phase arrest of the cell cycle and apoptosis. Treatment with $2 \mu \mathrm{M}$ AMA presumably induced arrest during all phases of the cell cycle. We have recently reported that AMA did not induce any specific phase arrest of the cell cycle in As4.1 juxtaglomerular cells (11) nor an S-phase arrest in cervical cancer HeLa cells (unpublished data). These results suggest that the inhibition of mitochondrial electron transport by AMA can alter cell cycle progression while the specificity of cell cycle arrest by AMA depends on differences in the cell type.

Susceptibility to AMA in relation to apoptosis is dependent on cell type. We recently reported that As4.1 juxtaglomerular cells were extremely sensitive, even to a $50 \mathrm{nM}$ concentration of AMA (16). The dose of $50 \mathrm{nM}$ cannot induce apoptosis in myelogenous leukemia HL-60 (12,25), HeLa (26), and our lung cancer A549 cells. The difference of susceptibility to AMA in various different cancer cell lines is probably due to the different basal activity of mitochondria in each cell line, since the activity of mitochondria is associated with a susceptibility to apoptosis $(27,28)$.

It has been reported that the collapse of mitochondrial membrane potential $\left(\Delta \Psi_{\mathrm{m}}\right)$ occurs during apoptosis (29). According to our data, AMA induced loss of the mitochondrial membrane potential $\left(\Delta \Psi_{\mathrm{m}}\right)$ in A549 cells. Notably, treatment with $50 \mu \mathrm{M}$ AMA causing apoptosis in A549 cells

Figure 4. Effects of AMA on intracellular ROS levels in A549 cells. Exponentially-growing cells were treated with the indicated amounts of AMA for $72 \mathrm{~h}$. The intracellular ROS levels were determined by a FACStar flow cytometer as described in Materials and methods. (A) The graph shows the levels of mean DCF fluorescence (general ROS) in AMA-treated cells. (B) The graph shows the levels of mean DHE fluorescence $\left(\mathrm{O}_{2}{ }^{-}\right)$in AMAtreated cells. ${ }^{*} \mathrm{P}<0.05$ compared with the AMA-untreated control cell group.

of $\sim 17 \%$ induced loss of the mitochondrial membrane potential $\left(\Delta \Psi_{\mathrm{m}}\right)$ at $\sim 38 \%$. This result suggests that AMA primarily damages the mitochondrial function, resulting in loss of the mitochondrial membrane potential $\left(\Delta \Psi_{\mathrm{m}}\right)$ and consequently inducing apoptosis.

AMA can disturb the natural oxidation/reduction equilibrium in cells by causing a breakdown in mitochondrial membrane potential $\left(\Delta \Psi_{\mathrm{m}}\right)(2,3,5)$. It has been reported that increased intracellular $\mathrm{H}_{2} \mathrm{O}_{2}$ plays an important role in AMAinduced cell death in liver cells $(30,31)$. Additionally, increases in $\mathrm{O}_{2}{ }^{-}$levels following exposure to AMA were reported in human lung epithelial (32) and As4.1 cells (11). These data suggest that the apoptotic effects of AMA are comparable to intracellular ROS levels, especially those of $\mathrm{H}_{2} \mathrm{O}_{2}$. Therefore, to elucidate the involvement of ROS such as $\mathrm{H}_{2} \mathrm{O}_{2}$ and $\mathrm{O}_{2}{ }^{-}$in AMA-induced A549 cell death, we assessed these ROS levels using $\mathrm{H}_{2}$ DCFDA and DHE fluorescence. Our data showed that the intracellular levels of general ROS increased in A549 cells. The $\mathrm{O}_{2}{ }^{-}$level also increased in AMA-treated A549 cells. Our results suggest that the changes of ROS by AMA are at least partially correlated with apoptosis in A549 cells. The exact mechanisms of cell death due to intracellular ROS in AMA-treated A549 cells still need to be defined further.

In conclusion, AMA inhibited the growth of human pulmonary adenocarcinoma A549 cells via inducing cell cycle arrest as well as triggering apoptosis. Growth inhibition in AMA-treated A549 cells was accompanied by the increase in ROS levels. Our results suggest that as a mitochondrial electron transport inhibitor, AMA, used with conventional drugs, is a candidate agent for treating lung cancer patients.

\section{Acknowledgements}

This study was supported by the Korean Science and Engineering Foundation (R01-2006-000-10544-0) and a Korea Research Foundation Grant funded by the Government of the Republic of Korea (MOEHRD). 


\section{References}

1. Nakayama K, Okamoto F and Harada Y: Antimycin A: isolation from a new streptomyces and activity against rice plant blast fungi. J Antibiot 9: 63-66, 1956.

2. Campo ML, Kinnally KW and Tedeschi H: The effect of antimycin A on mouse liver inner mitochondrial membrane channel activity. J Biol Chem 267: 8123-8127, 1992.

3. Pham NA, Robinson BH and Hedley DW: Simultaneous detection of mitochondrial respiratory chain activity and reactive oxygen in digitonin-permeabilized cells using flow cytometry. Cytometry 41: 245-251, 2000

4. Alexandre A and Lehninger AL: Bypasses of the antimycin a block of mitochondrial electron transport in relation to ubisemiquinone function. Biochim Biophys Acta 767: 120-129, 1984.

5. Balaban RS, Nemoto $\mathrm{S}$ and Finkel T: Mitochondria, oxidants, and aging. Cell 120: 483-495, 2005.

6. Panduri V, Weitzman SA, Chandel NS and Kamp DW: Mitochondrial-derived free radicals mediate asbestos-induced alveolar epithelial cell apoptosis. Am J Physiol Lung Cell Mol Physiol 286: L1220-L1227, 2004.

7. Zorov DB, Juhaszova M and Sollott SJ: Mitochondrial ROSinduced ROS release: An update and review. Biochim Biophys Acta 1757: 509-517, 2006.

8. Wilcox CS: Reactive oxygen species: roles in blood pressure and kidney function. Curr Hypertens Rep 4: 160-166, 2002.

9. Petronilli V, Penzo D, Scorrano L, Bernardi P and Di Lisa F: The mitochondrial permeability transition, release of cytochrome $\mathrm{c}$ and cell death. Correlation with the duration of pore openings in situ. J Biol Chem 276: 12030-12034, 2001.

10. Pastorino JG, Tafani M, Rothman RJ, Marcinkeviciute A, Hoek JB and Farber JL: Functional consequences of the sustained or transient activation by Bax of the mitochondrial permeability transition pore. J Biol Chem 274: 31734-31739, 1999.

11. Han YW, Kim SZ, Kim SH and Park WH: The changes of intracellular $\mathrm{H}_{2} \mathrm{O}_{2}$ are an important factor maintaining mitochondria membrane potential of antimycin A-treated As4.1 juxtaglomerular cells. Biochem Pharmacol 73: 863-872, 2007.

12. King MA: Antimycin A-induced killing of HL-60 cells: apoptosis initiated from within mitochondria does not necessarily proceed via caspase 9. Cytometry A 63: 69-76, 2005.

13. Wolvetang EJ, Johnson KL, Krauer K, Ralph SJ and Linnane AW: Mitochondrial respiratory chain inhibitors induce apoptosis. FEBS Lett 339: 40-44, 1994.

14. Kaushal GP, Ueda N and Shah SV: Role of caspases (ICE/CED 3 proteases) in DNA damage and cell death in response to a mitochondrial inhibitor, antimycin A. Kidney Int 52: 438-445, 1997.

15. de Graaf AO, Meijerink JP, van den Heuvel LP, et al: Bcl-2 protects against apoptosis induced by antimycin $\mathrm{A}$ and bongkrekic acid without restoring cellular ATP levels. Biochim Biophys Acta 1554: 57-65, 2002.

16. Park WH, Han YW, Kim SW, Kim SH, Cho KW and Kim SZ: Antimycin A induces apoptosis in As4.1 juxtaglomerular cells. Cancer Lett 251: 68-77, 2007.
17. Kastan MB and Bartek J: Cell-cycle checkpoints and cancer. Nature 432: 316-323, 2004.

18. Coqueret O: New roles for p21 and p27 cell-cycle inhibitors: a function for each cell compartment? Trends Cell Biol 13: 65-70, 2003.

19. Massague J: G1 cell-cycle control and cancer. Nature 432 298-306, 2004.

20. Shackelford RE, Kaufmann WK and Paules RS: Oxidative stress and cell cycle checkpoint function. Free Radic Biol Med 28: 1387-1404, 2000.

21. Boonstra J and Post JA: Molecular events associated with reactive oxygen species and cell cycle progression in mammalian cells. Gene 337: 1-13, 2004

22. Petty RD, Nicolson MC, Kerr KM, Collie-Duguid E and Murray GI: Gene expression profiling in non-small cell lung cancer: from molecular mechanisms to clinical application. Clin Cancer Res 10: 3237-3248, 2004.

23. Park WH, Seol JG, Kim ES, et al: Arsenic trioxide-mediated growth inhibition in MC/CAR myeloma cells via cell cycle arrest in association with induction of cyclin-dependent kinase inhibitor, p21, and apoptosis. Cancer Res 60: 3065-3071, 2000.

24. Han YH, Kim SZ, Kim SH and Park WH: Arsenic trioxide inhibits growth of As4.1 juxtaglomerular cells via cell cycle arrest and caspase-independent apoptosis. Am J Physiol Renal Physiol 293: F511-F520, 2007.

25. King MA and Radicchi-Mastroianni MA: Antimycin A-induced apoptosis of HL-60 cells. Cytometry 49: 106-112, 2002.

26. Park WH, Han YW, Kim SH and Kim SZ: An ROS generator, antimycin A, inhibits the growth of HeLa cells via apoptosis. J Cell Biochem 102: 98-109, 2007.

27. Jia L, Allen PD, Macey MG, Grahn MF, Newland AC and Kelsey SM: Mitochondrial electron transport chain activity, but not ATP synthesis, is required for drug-induced apoptosis in human leukaemic cells: a possible novel mechanism of regulating drug resistance. Br J Haematol 98: 686-698, 1997.

28. Sharkey SM, Wilson BC, Moorehead R and Singh G: Mitochondrial alterations in photodynamic therapy-resistant cells. Cancer Res 53: 4994-4999, 1993.

29. Yang J, Liu X, Bhalla K, et al: Prevention of apoptosis by Bcl-2: release of cytochrome $\mathrm{c}$ from mitochondria blocked. Science 275: 1129-1132, 1997.

30. Chen HM, Ma HH and Yan XJ: (Inhibitory effect of agarohexaose on antimycin $\mathrm{A}$ induced generation of reactive oxygen species). Yao Xue Xue Bao 40: 903-907, 2005.

31. Chen HM and Yan XJ: Antioxidant activities of agarooligosaccharides with different degrees of polymerization in cell-based system. Biochim Biophys Acta 1722: 103-111, 2005.

32. Li C, Wright MM and Jackson RM: Reactive species mediated injury of human lung epithelial cells after hypoxiareoxygenation. Exp Lung Res 28: 373-389, 2002. 